\title{
ÉOLO MAIA E A ARQUITETURA PÓS-MODERNA MINEIRA
}

Leila Barchi Domingues; Juliana Oliveira Ganzela; Korina Aparecida Da Costa Teixeira Ferreira.

Universidade do Oeste Paulista - UNOESTE, Curso de Arquitetura e Urbanismo, Presidente Prudente, SP. E-mail: barchileila@hotmail.com; julianaganzela@gmail.com.

\section{RESUMO}

O presente artigo constitui uma pesquisa qualitativa, do tipo revisão bibliográfica que analisa vida e obra do arquiteto Éolo Maia, um dos grandes nomes da produção arquitetônica brasileira do período pós-ditadura, fazendo parte de um grupo de arquitetos que tinham sua arquitetura caracterizada como pós-modernismo mineiro. A partir da Capela de Santana do Pé do Morro e de demais obras, busca-se traçar as características que teve sua arquitetura em diferentes fases e contradições devido as suas referências e assimilações em suas obras, além de identificar a relação de sua obra com a paisagem e sua produção com as dos demais arquitetos do seu tempo com o contexto arquitetônico presente de pós-ditadura e tentativa de superação do movimento moderno que se fazia latente, e também a sua significância para o período.

Palavras chave: Pós-modernismo brasileiro, Capela Pé do Morro, Três Arquitetos, Maia Arquitetos, Construção da paisagem.

\section{ÉOLO MAIA AND POST-MODERN ARCHITECTURE MINEIRA}

\section{ABSTRACT}

The present article is a qualitative research, of the type bibliographical review that analyzes the life and work of the architect Éolo Maia, one of the great names of the Brazilian architectural production of the period after the dictatorship, being part of a group of architects that had their architecture characterized as post -Mineralism. From the Chapel of Santana do Pé do Morro and other works, it is sought to trace the characteristics that had its architecture in different phases and contradictions due to its references and assimilations in his works, besides identifying the relation of his work with the landscape and its production with those of other architects of his time with the present architectural context of post-dictatorship and attempt to overcome the modern movement that became latent, and also its significance for the period.

Keyworks : Brazilian postmodernism, Capela Pé do Morro, Três Arquitetos, Maia Architects, Construction of the landscape. 


\section{INTRODUÇÃO}

Para tratar da arquitetura desse período pós-ditadura, é necessário antes fazer um resgate de sua evolução desde antes desse período de estagnação no país. É possível estabelecer paralelos entre o Brasil e outras nações latino-americanas tanto no campo arquitetônico quanto no social e político, essas nações que antes tinham sua arquitetura baseada em padrões europeus e posteriormente americano, buscavam uma renovação, a qual se fez lenta. (BENEVOLO, 2007)

Junto a falência do discurso modernizador militar, houve uma assimilação de debates internacionais sobre o pós-moderno os quais estavam envolvidas as teorias de Robert Venturi e Aldo Rossi. Isso então gerou-se um sentimento anti-moderno e a busca de uma nova expressão arquitetônica. (GONÇALVES E BARROS, 2016)

O regime militar instalado no Brasil em 1964 provocou vinte anos de estagnação cultural, mas, ao mesmo tempo, também isolou a área de arquitetura do movimento pós-moderno que envolvia todo o mundo naquela época. (BISSELI, 2011, s/p).

A chamada arquitetura pós-moderna brasileira se reflete em grande parte na adoção dos elementos formais mais óbvios da manifestação norte-americana do movimento. No caso brasileiro, destacamos o surgimento do grupo de arquitetos mineiros, que hoje consolida-se como o mais expressivo da pós-modernidade brasileira, e procuramos sugerir algumas razões para este fenômeno. Por fim, discutimos o caráter contraditório desta produção, relacionando-o inclusive com o novo elo que se estabelece nos tempos que correm entre cultura e política. (MARQUES, 1999)

Éolo Maia, por sua vez, adota como estilo alguns elementos da arquitetura do americano Michael Graves e um largo repertório de outras referências em sua arquitetura. Ainda que criticada pela fragilidade de sua base teórica, a adoção do "pós-modernismo" como estilo teve o importante papel de atenuar a hegemonia da arquitetura moderna no Brasil, apontando a possibilidade de novos rumos. (PAIM et al, 2016).

Não me classifico como nada, porque não tenho nada predeterminado, só sei que quero fazer arquitetura com prazer e contemporaneidade. A vida é muito dinâmica, eu mudo todo dia, e a arquitetura é uma expressão cultural que se reflete em meu trabalho. As fórmulas se tornam uma chatice, e a ânsia de estar na onda é um erro. Não se pode ser fechado, dogmático. É preciso ter liberdade total. (ROCHA, 2002, p.1)

\section{METODOLOGIA}

A presente pesquisa de grau qualitativo, tem como embasamento pesquisas de revisões bibliográficas, análises, e aplicações do método projetual do arquiteto Éolo Maia, juntamente com o estudo do conceito da pós modernidade.

\section{RESULTADOS}

$\mathrm{O}$ arquiteto brasileiro Éolo Maia nasceu em Ouro Preto, no estado de Minas Gerais, no ano de 1942, cidade onde descobriu a arquitetura (ROCHA, 2002). Foi na cidade natal que iniciou seus estudos com cursos técnicos na Escola de Minas, mas foi na UFMG em Belo Horizonte em 1963 que deu início à sua jornada na arquitetura, graduando-se em 1967. Na época, ainda sob a repressão militar, suas obras haviam conceitos espaciais e plásticos do brutalismo, como também o emprego de materiais em aspecto crus, como seu primeiro projeto a Residência Marcos Tadeu (1966-1967), que em 1970 recebeu prêmio na III Premiação Anual do IAB-MG. (SANTA CECILIA, 2009).

Trabalhou no início da carreira com João Filgueiras Lima Lelé e Villanova Artigas. Esse período marcou sua primeira fase com intensivo uso de concreto armado, pela construção de volumes prismáticos e regulares. É exemplar dessa fase a Residência João Henrique Grossi, 1969, em Belo Horizonte. No início dos anos 1970, passa a ter como influência predominante a obra de Louis I. Kahn (1901 - 1974), lançando mão de aberturas em formas geométricas puras, 
como na Residência Renan Alvim, 1971, em seguida, parte para a exploração de volumetrias mais livres, como o prisma triangular da Residência Hélio Carvalho, 1978, ambas em Belo Horizonte. (SANTA CECILIA, 2009).

Em 1981 o grupo Três Arquitetos formados por Éolo, Jô Vasconcelos e Sylvio de Podestá. Criou em 1982 a revista Pampulha onde as publicações sobre a arquitetura mineira ganhavam força. Desse grupo, teve como frutos grandes projetos como Escola Primária Vale Verde em Timóteo-MG (1981-1984) e a Centro de Apoio Turístico Tancredo Neves, em Belo Horizonte (1984). (CALDEIRA, 2002).

Em 1989 funda o escritório Maia Arquitetos Associados, época classificada como sua última fase até 2002, ano de seu falecimento. Éolo trabalhou com a verticalidade, realizadas sob pesquisas tecnológicas e formais, construindo uma série de edifícios verticais de grande porte, como o Centro Empresarial Raja Gabaglia e o Condomínio Officenter, 1989, e o edifício Le Corbusier, 1991, e a Academia Wanda Bambirra (1997-1998) todos em Belo Horizonte.

Apesar de não se classificar um arquiteto pós-modernista, a arquitetura com prazer e contemporaneidade tornou Éolo Maia um expoente da arquitetura brasileira e um dos arquitetos mais proeminentes de sua geração. (ROCHA, 2002).

Seu talento para criar marcos e referências urbanas surgiu após se aprofundar nos conceitos barrocos que definiam o local simbolicamente. Assim, em seus edifícios não há como não notar aquilo que Kevin Lynch (1960, p.10) denominava "imaginabilidade", ou seja, a capacidade que um objeto físico possui de evocar uma imagem ou sensação forte. Considerava que a paisagem das cidades não apenas era formada pela imagem dos edifícios que as compõem, mas, principalmente, pelas relações que estes edifícios estabelecem entre si e entre os espaços vazios que os circundam.

Para isso, adotou características que contribuíssem para a melhor construção da imagem urbana, dentre elas podemos destacar a dimensão vertical, na qual era um atributo muito utilizado para garantir sua visibilidade e obter a diferenciação dos edifícios vizinhos. Essas composições de volumes verticais muitas vezes possuíam ou formas escultóricas ou princípio da tripartição (base, corpo e coroamento). (SANTA CECILIA, 2009).

Além disso, suas obras possuem expressividade plástica, que são composições com volumes plasticamente expressivos obtidos através formas livres e uma composição autônoma na parte externa do edifício. Isso devido a sua capacidade de assimilar, criativamente, todas as tendências da arquitetura nacional e internacional. Era nesse aspecto que ele se revelava um grande arquiteto-autor, quando fazia emergir a originalidade da própria criação em meio a tantas influências. (MALARD, 2006).

Juntamente com a construção de edifícios heterogêneos e estudos da paisagem e seu entorno, Éolo Maia levou para suas obras a capacidade de sensibilizar o usuário, a recuperação do diálogo com as pessoas que supostamente havia se perdido em virtude do caráter hermético dos discursos da arquitetura moderna, fez com que sua arquitetura se tornasse mais comunicativa. (MALARD, 2006)

\section{DISCUSSÃO}

Nas principais obras de Éolo Maia percebe-se as preocupações com o espaço, muito bem pensados, flexíveis e, em geral organizados por meio de eixos de circulação. Prioriza a visão do exterior, da paisagem, a luz tropical, imprimi ritmos e cores vibrantes aos volumes.

Dentre elas, o condomínio Tinguá (1968-70) é um dos primeiros projetos assinados pelo arquiteto mineiro. De escala e feições modestas, seu aparente recado deve-se à regularidade da fachada frontal além da proximidade dos prédios vizinhos que the ocultam o volume bem proporcionado. (SANTA CECILIA, 2011). 
Uma de suas obras mais divulgadas pela originalidade foi, sem dúvidas, a casa arquiepiscopal de Mariana (1982-83), pela sua convivência pacífica entre "períodos históricos". A fim de manter a harmonia do espaço urbano, nas fachadas, segundo o arquiteto, marcos e quadros de aço significam a representação contemporânea das antigas estruturas de madeira. Os ritmos dos vãos estão de acordo com a proporcionalidade dos cheios e vazios da cidade e, um pátio interno amplo e generoso complementa internamente a construção. (PODESTÁ, 2016)

O Centro De Apoio Turístico Tancredo Neves (1984-1992), mais conhecido como Rainha da Sucata, é revestido materiais ligados à construção e à indústria mineira, como as chapas metálicas enferrujadas que lhe sugeriram o apelido. O edifício é considerado por Maia o exemplo mais significativo da arquitetura pós-moderna produzida em Minas Gerais. Com uma linguagem própria, trazendo uma inquietação em novas formas e tecnologia, conclui-se que este edifício foi implantado com uma singularidade obtida pelos resultados dos volumes, que visavam gerar um novo significado na estrutura espacial da praça da liberdade, tornando-o um marco e referência urbana na arquitetura brasileira. (PODESTÁ, 2016b)

\section{ANÁLISE DA CAPELA DE SANTANA DO PÉ-DO-MORRO}

A obra capela de Santana do Pé do Morro está localizada em uma fazenda perto da cidade mineira de Ouro Branco, mais especificamente na Estrada Real, lugar marcado pela história do período colonial do séc. XVIII. Essa obra marca uma ruptura de linguagem, em direção à liberdade de expressão plástica que o conduziu Éolo às críticas pós-modernas.

Usada por viajantes e mineradores a capela foi construída a fim de abrigar uma imagem sacra de grande valor histórico e artístico da época, em sua proposta de criação a Capela De Santana Do Pé-do-Morro aproveita as ruínas de uma antiga edificação de uma forma peculiar, transformando as próprias ruínas no altar para a capela.

Seus autores Éolo Maia e Jô Vasconcellos agregaram a matriz conceitual que pressupunha a clara diferenciação entre elementos novos e antigos na capela, através do uso de materiais contemporâneos e da autonomia formal dos novos elementos. (SANTA CECÍLIA, 2004).

O interior é organizado por um eixo longitudinal dominante no sentido leste-oeste, no centro há a imagem de Santana e uma pia batismal em forma de uma esfera maciça que simboliza o encontro do homem com sua fé. As locações de painéis decorativos coloridos no altar fazem uma releitura contemporânea dos antigos vitrais, assim, a capela produz a sensação de leveza visual, caracterizada pela sua simplicidade e pertencimento ao local com suas belezas memoráveis. (SANTA CECÍLIA, 2004).

Entre os materiais e elementos construtivos, se tem as ruínas históricas de pedra São Thomé, boa parte da capela possui piso em quartzito, as laterais são envidraçadas de vidro fumê e os caibros são envernizados. Na estrutura e no cruzeiro o aço corten tem a característica da cor da terra mineira, sua composição possui alta resistência a corrosão atmosférica, permitindo assim seu uso em ambientes rurais. (SANTA CECILIA, 2004).

Como observa Santa Cecília (2004) o esqueleto estrutural do edifício é composto por elementos portantes metálicos verticais e horizontais: pilares, vigas e vergas. Ela se assemelha à um galpão por seu invólucro construtivamente simples e formal jogando toda a tensão e a força expressiva da capela para o invólucro exterior, surgindo assim um volume triangular que demarca externamente o limite nave e altar. Do lado de fora um tanque de água oval permite que a imagem da edificação apareça refletida, a escala e a simplicidade da forma harmonizam com a solidez das ruínas que são envolvidas pela estrutura.

Podemos fazer a alusão dessa capela à tipologia miesiana do pavilhão de aço e vidro, porém adaptando-a ao uso religioso. Além disso, a estratégia do um invólucro simples, permite que as ruínas se mantenham como o elemento mais importante do espaço. (SANTA CECILIA, 
2014). Na capela a postura tectônica se faz presente já que os procedimentos construtivos são deixados visíveis, destacando toda a beleza e as qualidades plásticas da estrutura em aço.

\section{CONCLUSÃO}

Éolo produziu uma arquitetura que não só atendia a função a ela dada, mas que buscava uma relação do edifício e os espaços que a ele circundam. Sua arquitetura contribuía com a imagem urbana, possuía expressividade plástica em meio sua originalidade. A obra analisada Capela de Santana do Pé do Morro declara a diferenciação do novo e antigo, da integridade do histórico e dos materiais contemporâneos. Com uma arquitetura que se adapta ao local, à economia e materiais locais.

$\mathrm{O}$ arquiteto teve diversas influências, e por fim, optou por uma arquitetura dinâmica, com uma expressão cultural, de forma que fez parte do grupo mais expressivo da pós-modernidade brasileira. Após a estagnação do país, com o sentimento anti-moderno, e apesar de não adimitirse pós-modernista, Éolo teve importante papel em apontar novos rumos, em atenuar a hegemonia da arquitetura do Brasil.

\section{REFERÊNCIAS}

BISELLI, Mario. Teoria e prática do partido arquitetônico. Arquitextos, São Paulo, ano 12, n. 134.00, Vitruvius, jul. 2011. Disponível em: <http://www.vitruvius.com.br/revistas/read/arquitextos/12.134/3974>. Acesso em 06 mar 2015.

BENEVOLO, Leonardo. Arquitetura do novo milênio. São Paulo: Estação Liberdade, 2007.

CALDEIRA, Altino Barbosa. Algumas verdades e mentiras sobre Éolo Maia. Vitrúvius, ano 03, n.029, 2002. Disponível em: <http://www.vitruvius.com.br/revistas/read/arquitextos/03.029/737>. Acesso em: 02 mar 2016.

GONÇALVES, Carla; BARROS, Luiz. Projetos publicados. Revista AU.

Disponível

em: <https://revistamdc.files.wordpress.com/2009/07/carlaaugustogoncalves_cicau.pdf> Acesso em : 12 mar 2016.

LYNCH, Kevin. A imagem da cidade. São Paulo: Martins Fontes, 1960.

MALARD, Maria Lúcia. A arquitetura de síntese de Éolo Maia. 2006. Disponível em: <http://www.vitruvius.com.br/revistas/read/resenhasonline/05.055/3137/>. Acesso em $04 \mathrm{mar}$ 2015.

MARQUES, Sônia. Arquitetura brasileira, uma Pós-Modernidade mais do que contraditória. RAURevista de Arquitetura e Urbanismo. v. 5, n. 1, 1999. Disponível em: < http://www.portalseer.ufba.br/index.php/rua/article/view/3138>. Acesso em: 02 mar 2016.

NORBERG-SCHULZ, Christian; DIGEROUD, George. Louis I. Kahn, idea e imagem. Madri: Xarait, 1981.

PAIM, A; CLÁUDIA, A; PIASSINI, D. O pós-moderno. Disponível em: <https://arquiteturadobrasil.wordpress.com/8-a-pos-modernidade/>. Acesso em 29 fev 2015. 
PODESTÁ, Sylvio de. 1982/83: Casa Arquiepiscopal de Mariana. 2016. Disponível em: $<$ http://www.podesta.arq.br/index.php/residenciais/119-projeto-casa-arquiepiscopal-demariana/>. Acesso em 05 mar 2015.

PODESTÁ, Sylvio de. 1982/83: Casa Arquiepiscopal de Mariana. 2016. Disponível em: $<$ http://podesta.arq.br/index.php/arquiteto?id=159:projeto-rainha-dasucata\&catid=1:residencias/>. Acesso em 04 mar 2015.

ROCHA, Silvério. Entrevista: Éolo Maia. 2002. Disponível em: $<$ https://arcoweb.com.br/projetodesign/entrevista/eolo-maia-01-05-2002>. Acesso em 04 mar 2015.

SANTA CECÍLIA, Bruno. Complexidade e contradição na arquitetura brasileira: a obra de Éolo Maia. 2004. Dissertação (Mestrado). UFMG: Escola de arquitetura, Belo Horizonte-MG, 2004.

SANTA CECÍlIA, Bruno. Éolo Maia e a construção da paisagem. 2009. Disponível em: <http://mdc.arq.br/2009/02/16/eolo-maia-e-a-construcao-da-paisagem/>. Acesso em 03 mar 2015.

SANTA CECÍlIA, Bruno. Edifício Tinguá - Éolo Maia. 2011. Disponível em: <http://www.arquitetosassociados.arq.br/?artigo=condominio-tingua-eolo-maia-2/>. Acesso em 14 mar 2015.

SANTA CECÍLIA, Bruno. Capela de Santana do Pé-do-morro, de Éolo Maia e Jô Vasconcellos. 2014.

Revista AU. Edição 247 - Outubro/2014. Disponível em: <http://au.pini.com.br/arquiteturaurbanismo/247/historia-em-detalhe-capela-de-santana-do-pe-do-morro-de-eolo-327507-1.aspx> Acesso em: 14 mar 2016. 